\title{
BASAL METATARSAL OSTEOTOMY FOR HALLUX VALGUS
}

DAVID C. BORTON, MICHAEL M. STEPHENS

From St Mary's Orthopaedic Hospital and the Mater Misercordiae Hospital, Dublin, Republic of Ireland

We performed basal chevron metatarsal osteotomy on 32 feet (31 patients) for painful hallux valgus associated with an increased intermetatarsal $1 / 2$ angle $\left(>12^{\circ}\right)$. Pedobarographic and radiological examinations were done preoperatively and at a minimum of six months postoperatively.

The average hallux valgus angle was improved from $40.9^{\circ}$ to $19.2^{\circ}$ and the intermetatarsal $1 / 2$ angle from $16.5^{\circ}$ to $6.8^{\circ}$. The mean angle of declination of the first metatarsal was decreased by $1.4^{\circ}$.

The pedobarographs showed a significant reduction in areas sustaining pressure $>5 \mathrm{~kg} / \mathrm{cm}^{2}$, an increased total foot contact area and a higher percentage forefoot contact area on heel raise. There was a high level of patient satisfaction with relief of symptoms and improved appearance of the foot.

J Bone Joint Surg [Br] 1994; 76-B:204-9.

Received 29 July 1993; Accepted 28 September 1993

Metatarsus primus varus is associated with hallux valgus and there is a close relationship between the degree of the two deformities (Hardy and Clapham 1951, 1952; Bonney and Macnab 1952). There is, however, no agreement on which is the primary deformity (Piggott 1960; Kelikian 1965). Distal metatarsal osteotomy in patients with splayed feet has led to high rates of patient dissatisfaction (Hattrup and Johnson 1985; Meier and Kenzora 1985) and we believe that feet with an intermetatarsal $1 / 2$ angle greater than $12^{\circ}$ require a basal osteotomy.

\section{PATIENTS AND METHODS}

Between February 1991 and October 1992, 31 patients with painful hallux valgus and an intermetatarsal (IM) $1 / 2$ angle $>12^{\circ}$ (mean $16.5^{\circ}$ ) had pedobarographic and

D. C. Borton, FRCS I, Orthopaedic Registrar

M. M. Stephens, MSc (BioEng), FRCS I, Consultant Orthopaedic Surgeon Mater Misercordiae Hospital, Eccles Street, Dublin 7, Republic of Ireland.

Correspondence should be sent to Mr M. M. Stephens at Suite 8, Mater Private Hospital, Eccles Street, Dublin 7, Republic of Ireland.

(C)1994 British Editorial Society of Bone and Joint Surgery $0301-620 X / 94 / 2756 \$ 2.00$ radiological assessment. There were 25 women (26 feet) and 6 men; their average age was 53.1 years ( 31 to 79). All had basal chevron metatarsal osteotomy.

Preoperatively, pain severity was documented by a visual analogue score graded from 0 to 10 . Dorsoplantar and lateral weight-bearing radiographs were taken and pedobarographs, using the Musgrave foot print system (W. M. Automation, Carrickfergus, Co. Antrim, UK), were performed (Vaughan, Davies and O'Connor 1992).

The indication for surgery was painful hallux valgus which did not respond to conservative treatment. No patient had degenerative arthritis of the first metatarsophalangeal (MTP) joint. Simultaneous procedures were performed on the lesser toes in 15 feet. One patient had bilateral osteotomies performed with nine months between the procedures.

The average follow-up was 9.9 months (6 to 21). At the postoperative review patients were asked to grade their feet for overall satisfaction, pain and cosmesis. Satisfaction and pain were assessed using a visual analogue score graded from 0 to 10 . Cosmesis was graded as either completely satisfied, satisfied with minor reservations or dissatisfied. Further dorsoplantar and lateral weight-bearing radiographs were obtained and from these the IM $1 / 2$ angle, hallux valgus angle and angle of declination of the first metatarsal were measured and compared with the preoperative radiographs. Pedobarography was repeated (Holmes, Timmerman and Willits 1991), adjusting the stride length and stance width for each patient. Areas of pressure $>5 \mathrm{~kg} / \mathrm{cm}^{2}$, the total contact area, the forefoot contact area on heel raise and the centre of load were recorded and compared with those from preoperative pedobarographs.

Statistical analysis was done on a Macintosh Classic computer using the paired $t$-test on Datadesk 3.0 software (Odesta Corporation, Northbrook, Illinois).

Operative technique. All the operations were performed under above-knee tourniquet after exsanguination. The first webspace is incised dorsally and the adductor tendon is released from the lateral sesamoid and the proximal phalynx. A dorsomedial incision is then made along the first metatarsal shaft avoiding the dorsal cutaneous nerve. The capsule of the MTP joint is incised longitudinally and the medial bony eminence resected from the metatarsal head using an oscillating saw. The bony exostosis is saved. 
A $60^{\circ}$ chevron osteotomy is fashioned with its apex $2 \mathrm{~cm}$ distal to the tarsometatarsal joint. The distal segment of the metatarsal is then plantar flexed, displaced laterally and held by wedging bone from the exostosis into the dorsal limb of the chevron. This maintains plantar flexion and supination and distracts the upper limb of the chevron (Fig. 1). An absorbable suture is passed through the first metatarsal head and the second metatarsal neck and tied to secure the correction. The adductor hallucis is reattached to the first metatarsal neck and the capsule is closed after capsulectomy to tighten it and draw the sesamoids medially (Fig. 2). The skin is closed over a vacuum drain. Postoperatively, the foot is placed in a plaster boot, non-weight-bearing for two weeks. Partial weight-bearing is allowed for two weeks and then full weight-bearing for a further two weeks. At six weeks the cast is removed and radiographs are taken to confirm union.

\section{RESULTS}

Subjective evaluation. All but one of the patients were satisfied with the procedure; 14 were completely satisfied and 17 were satisfied with minor reservations. The one patient who was dissatisfied was a marathon runner who continued to have pain on running long distances. The mean satisfaction on the visual analogue score was $8.2 \pm 2.0$. Five of the 15 patients who had had surgery on the lesser toes as well were completely satisfied with the

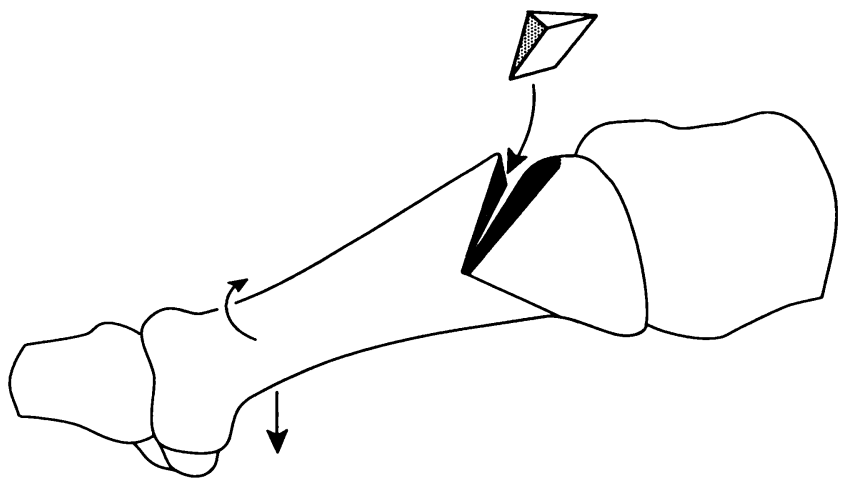

Fig. 1

Diagram showing the insertion of a bone wedge into the upper limb of the chevron to distract, supinate and plantar flex the metatarsal.

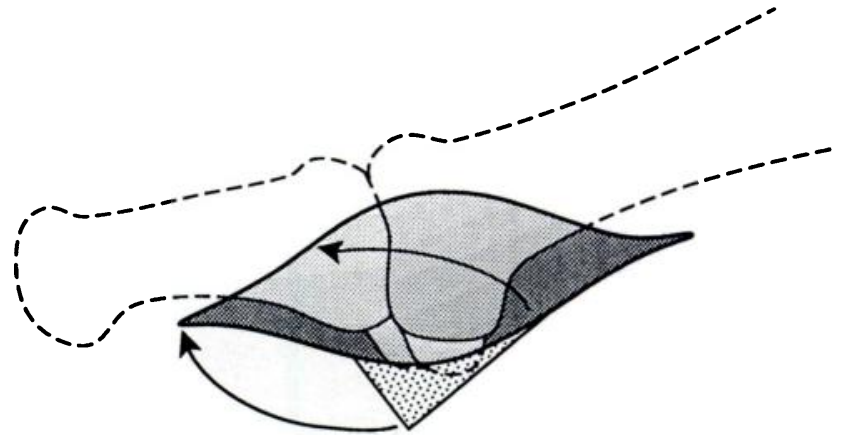

Fig. 2

Diagram showing capsulectomy (dotted area) and closure of the capsule to tighten the medial capsule and draw the sesamoids medially.
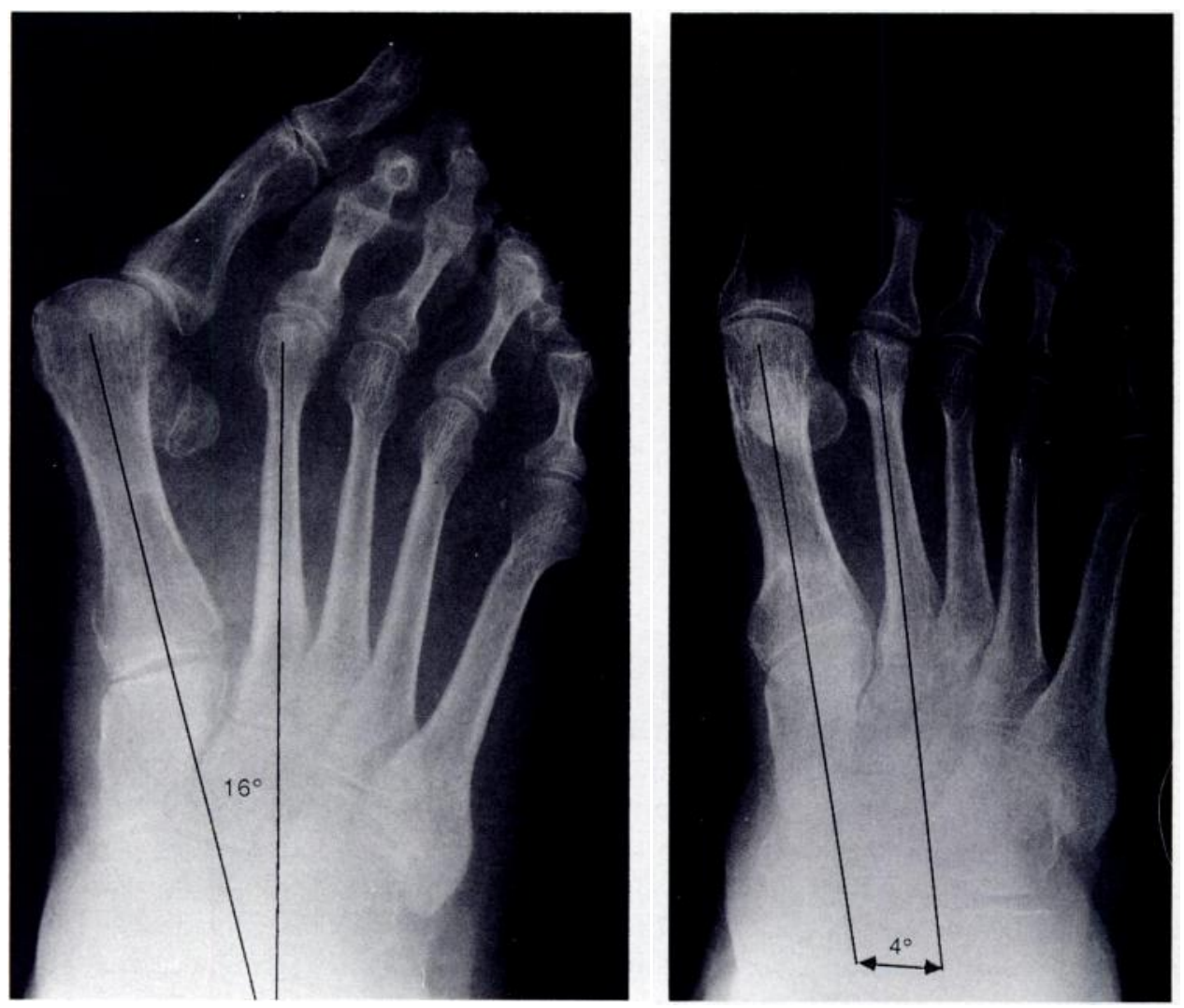

Pre- and postoperative dorsoplantar weight-bearing radiographs showing that the intermetatarsal $1 / 2$ angle is reduced from $16^{\circ}$ to $4^{\circ}$.

Fig. 3 


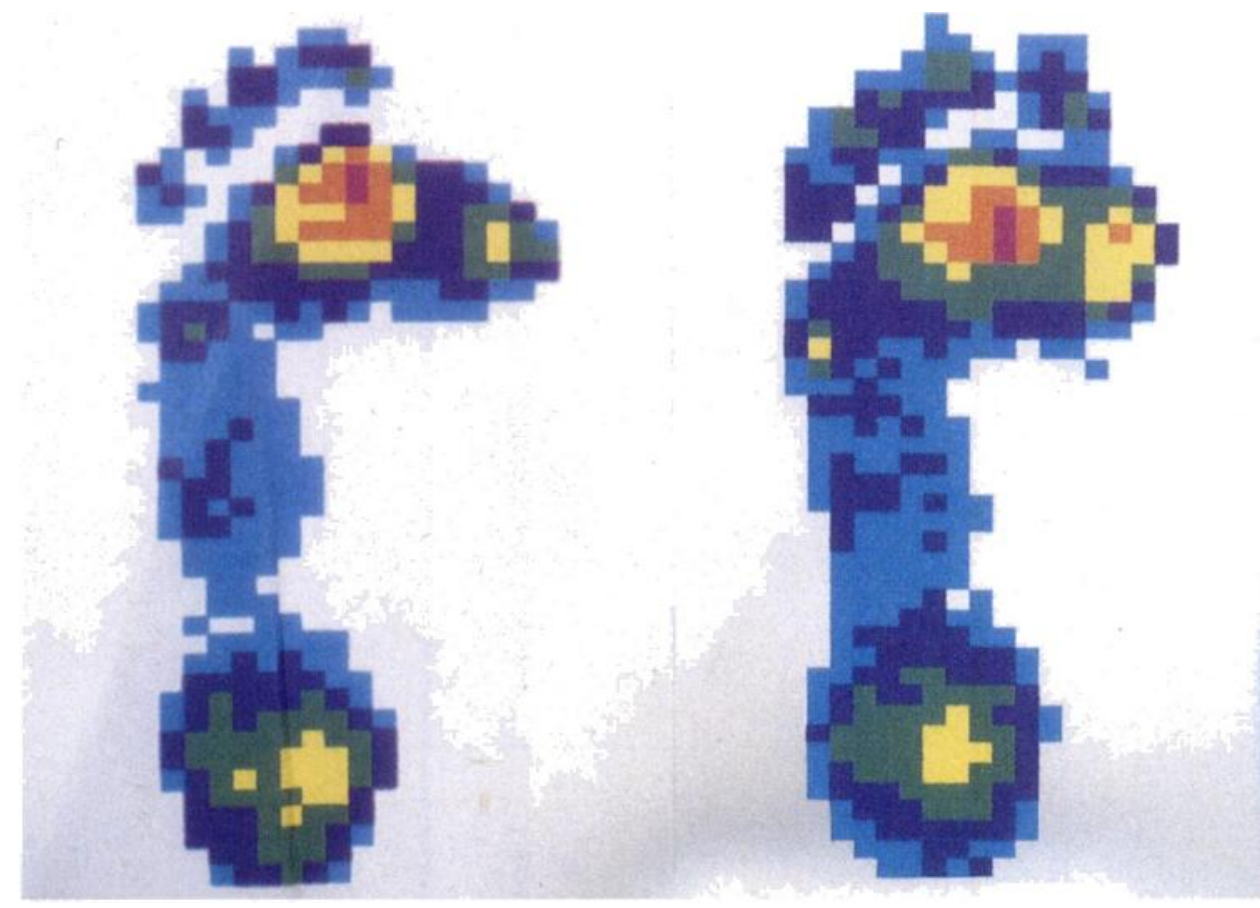

Fig. 4

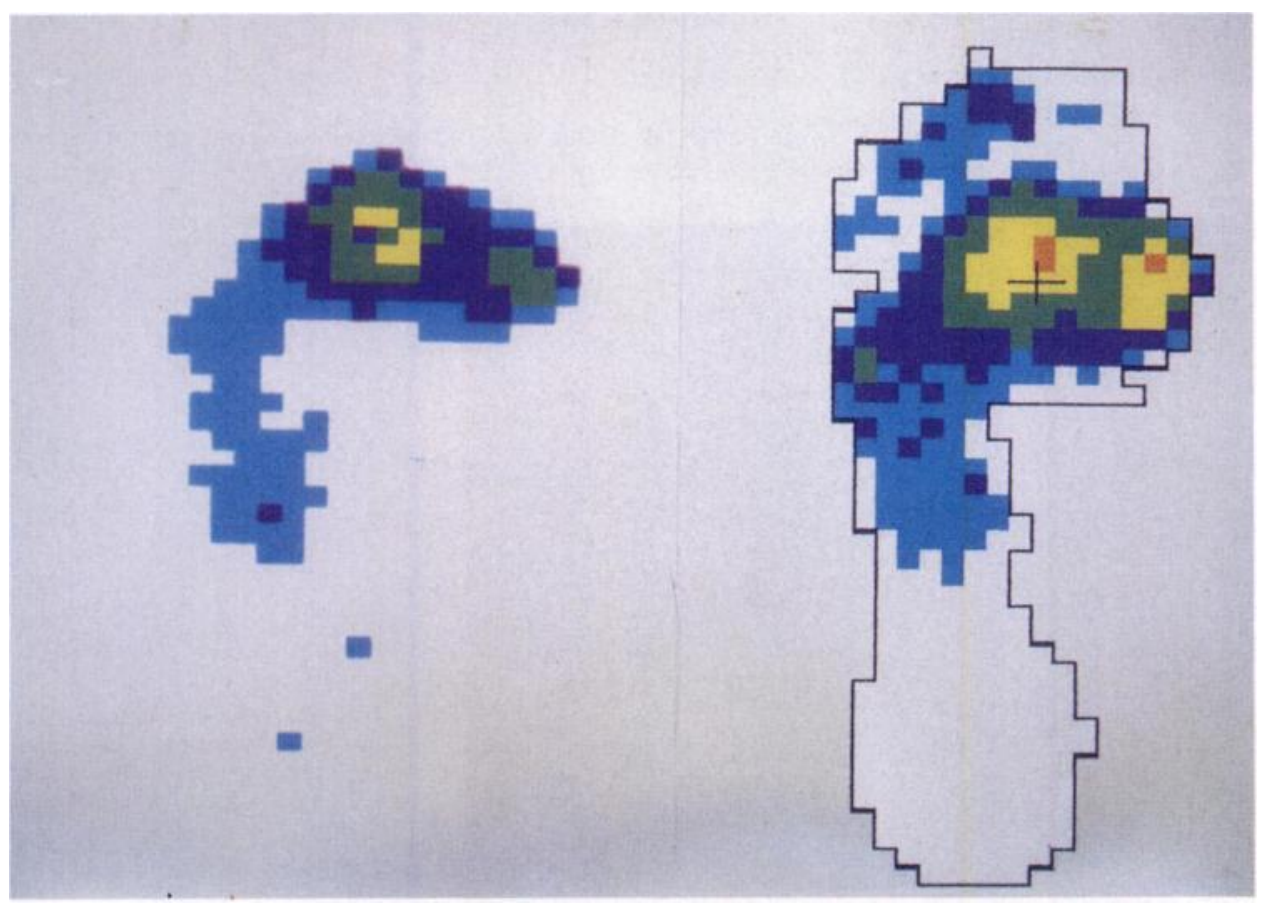

Fig. 5

main operation but had minor reservations about stiffness in the lesser toes.

Pain was eased in all but one patient. Twenty-two feet were painfree and nine had occasional, minor pain. The pain scores improved from a mean of $4.7 \pm 2.2$ preoperatively to a mean of $1.1 \pm 1.5$ postoperatively. All but one of the patients were pleased with the cosmetic result; 23 were completely satisfied and 8 were satisfied with minor reservations. One patient developed hallux
Pre- and postoperative pedobarographs showing that the total contact area is increased by $14.2 \%$.
Pre- and postoperative pedobarographs showing that the forefoot contact area on heel raise is increased by $20.1 \%$. varus and although free from pain was dissatisfied with the appearance of the foot.

Radiography. The mean IM $1 / 2$ angle improved from $16.5^{\circ} \pm 2.6^{\circ}$ to $6.8^{\circ} \pm 3.2^{\circ}$, a mean correction of $9.7^{\circ}$. The hallux valgus angle improved from $40.9^{\circ} \pm 8.3^{\circ}$ to $19.2^{\circ} \pm 9.4^{\circ}$, a mean correction of $21.7^{\circ}$ (Fig. 3 ). The mean postoperative hallux valgus angles were calculated after excluding two patients who developed hallux varus of $13^{\circ}$ and $27^{\circ}$. Their inclusion would have given an average 
hallux valgus angle of $16.7^{\circ}$ which would have been misleading. Sesamoid staging (Haines and McDougall 1954) improved from an average of 3 to 1.2. Preoperatively, the mean arch angle of the first metatarsal was $22.8^{\circ} \pm 3.1^{\circ}$ and decreased to $21.4^{\circ} \pm 3.2^{\circ}$ postoperatively, giving a mean decrease in the angle of declination of $1.4^{\circ}$. The osteotomies had all united by six weeks without problems.

Pedobarography. Preoperatively, the total contact area averaged $85.0 \mathrm{~cm}^{2} \pm 13.0 \mathrm{~cm}^{2}$; postoperatively, it increased area this represents an increase from $50.6 \% \pm 5.1 \%$ to $53.5 \% \pm 4.3 \%$, a mean increase of $5.7 \%(p<0.01)$.

The average number of sensors measuring pressures $>5 \mathrm{~kg} / \mathrm{cm}^{2}$ was reduced from $6.1 \pm 4.1$ to $4.4 \pm 3.2$, a decrease of $27.9 \%$ (Fig. 6; $p<0.05$ ). Preoperatively, the centre of load tended to lie laterally with loading during the propulsive phase through the third metatarsal head. Postoperatively, the centre of load was more medial with propulsive phase loading through the first interdigital cleft (Fig. 7).

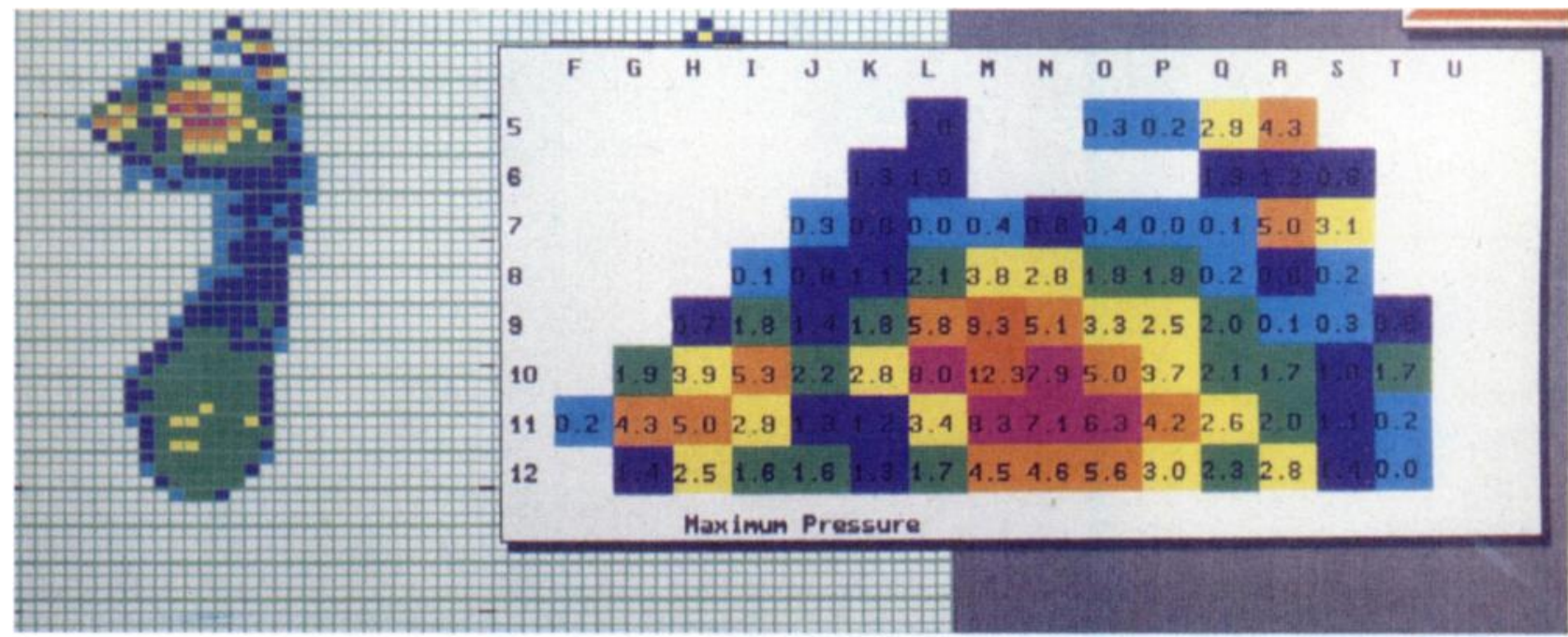

Fig. 6a

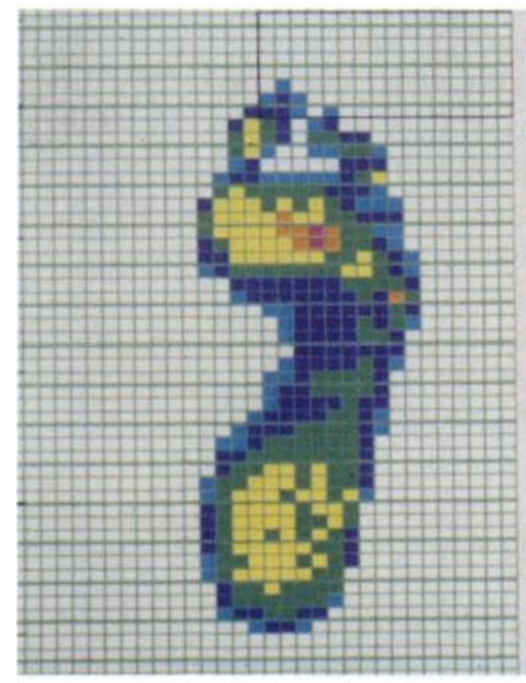
Preoperative (a) and postoper
sensors recording $>5 \mathrm{~kg} / \mathrm{cm}^{2}$.

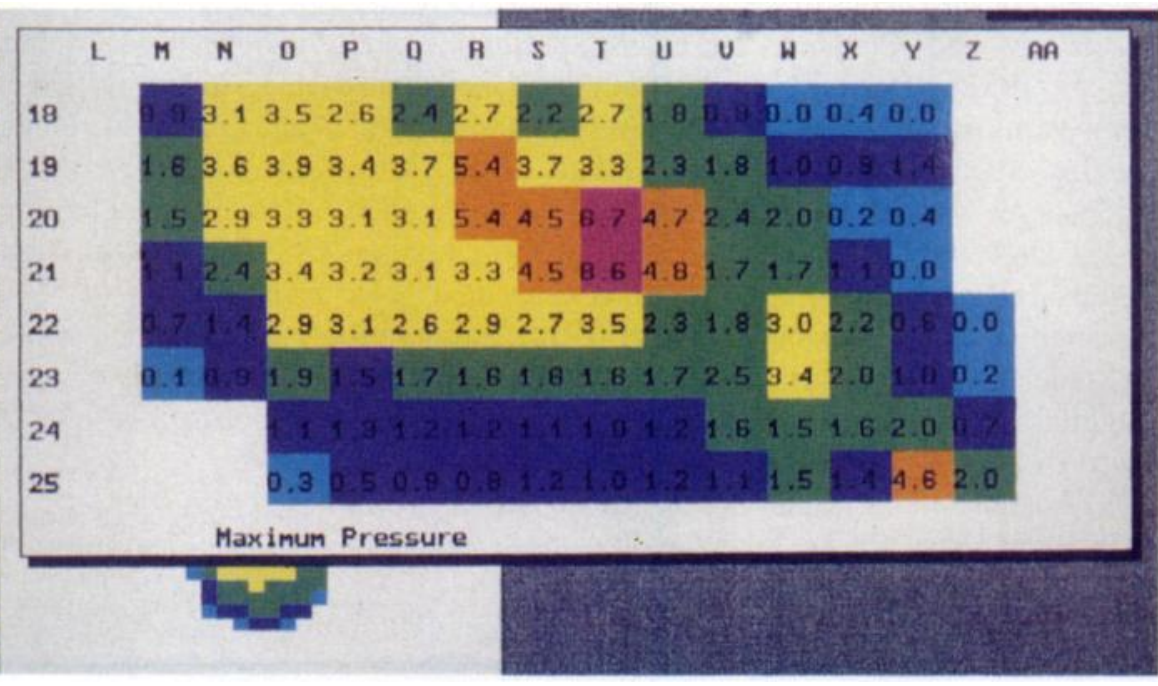

Fig. 6b by $14.2 \%$ to $97.1 \mathrm{~cm}^{2} \pm 13.9 \mathrm{~cm}^{2}$ (Fig. 4 ; p < 0.001 ). The mean forefoot contact area on heel raise increased by $20.1 \%$ from $43.3 \mathrm{~cm}^{2} \pm 9.3 \mathrm{~cm}^{2}$ to $52.0 \mathrm{~cm}^{2} \pm 9.1 \mathrm{~cm}^{2}$ (Fig. $5 ; \mathrm{p}<0.001)$. Expressed as a percentage of total contact
Complications. No patient developed infection. Four have slight discomfort at the osteotomy site due to excess callus and two developed a hallux varus deformity, one of $13^{\circ}$ and the other of $27^{\circ}$. The patient with the greater 

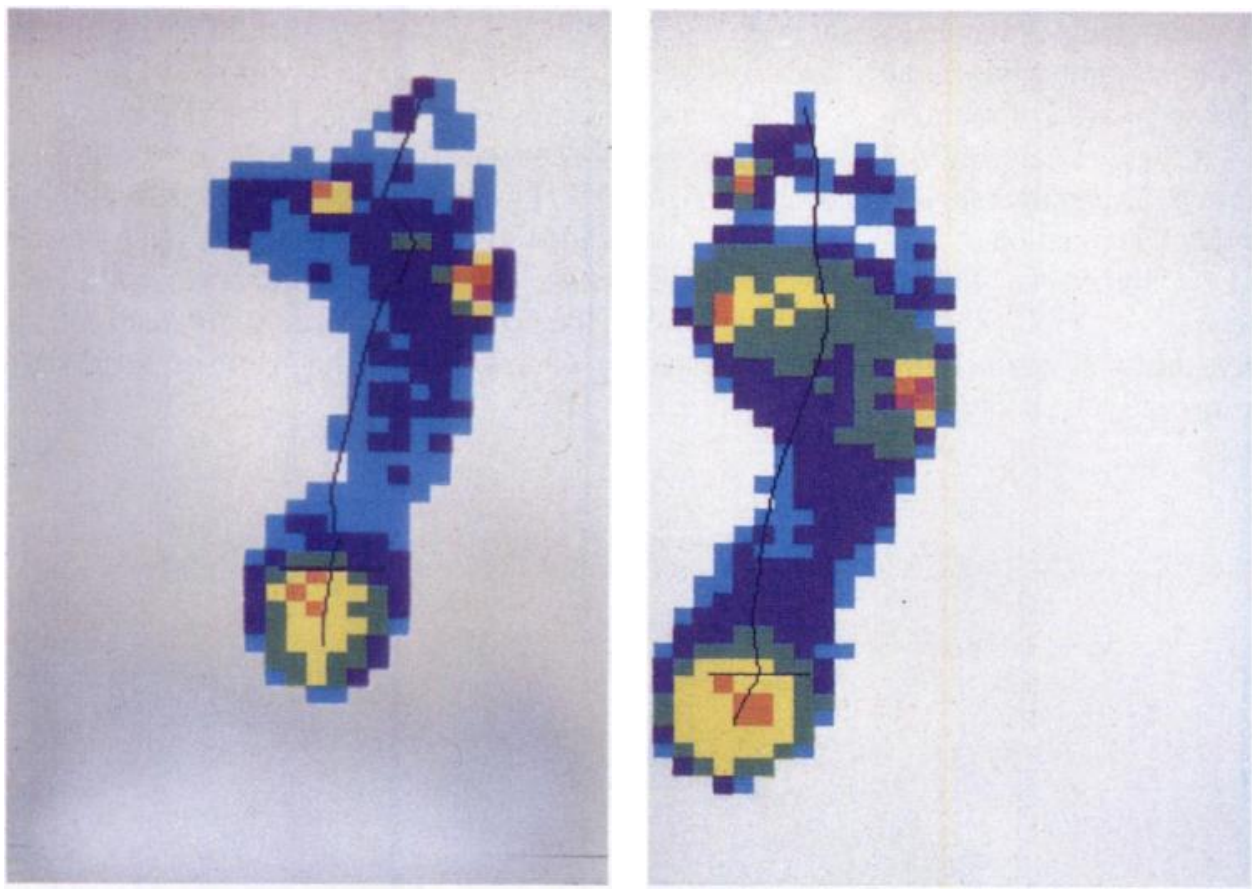

Fig. 7

Pre- and postoperative pedobarographs showing medialisation of the centre of load and a more normal pattern during the propulsive phase of walking. deformity had no complaints while the other, although painfree, was dissatisfied with the cosmetic outcome.

\section{DISCUSSION}

Hallux valgus has been widely reported to be associated with metatarsus primus varus (Antrobus 1984; Kilmartin, Barrington and Wallace 1991) and there appears to be a close relationship between the extent of the two deformities (Hardy and Clapham 1951, 1952; Bonney and Macnab 1952). Debate remains whether metatarsus primus varus predisposes to or is a result of hallux valgus (Truslow 1925; Piggott 1960; Kelikian 1965). Most authors agree that patients with hallux valgus and a wide IM 1/2 angle require some procedure at the proximal metatarsal. Basal osteotomies of various kinds have been advocated; wedge excision (Lapidus 1934; Simmonds and Menelaus 1960; Golden 1961), crescentic (Mann and Coughlin 1986; Thordarson and Leventen 1992), and chevron (Corless 1976; Johnson, Cofield and Morrey 1979; Austin and Leventen 1981; Meier and Kenzora 1985; Richardson 1992). Some authors have favoured metatarsocuneiform arthrodesis (Myerson, Allon and McGarvey 1992) or a cuneiform osteotomy (Rocyn Jones 1948).

It has been shown that patients with varus deviation of the first metatarsal have first metatarsal pronation and that the degree of rotation is related to the IM $1 / 2$ angle (Eustace et al 1993). These facts coupled with the problem of metatarsus elevatus (Thordarson and Leventen 1992) after basal osteotomy, suggest that it is necessary to supinate and to plantar flex the metatarsal at the site of the osteotomy. The bone wedge taken from the exostosis and placed in the dorsal limb of the chevron supinates, plantar flexes and distracts the distal metatarsal. Internal fixation is not required as the distraction of the upper limb of the chevron tightens the soft tissues and provides stability.

Basal chevron osteotomy, performed as we describe, has proved effective in relieving symptoms and in restoring feet to nearly normal shape and function.

No benefits in any form have been received or will be received from a commercial party related directly or indirectly to the subject of this article.

\section{REFERENCES}

Antrobus JN. The primary deformity in hallux valgus and metatarsus primus varus. Clin Orthop 1984; 184:251-5.

Austin DW, Leventen EO. A new osteotomy for hallux valgus. Clin Orthop 1981; 157:25-30.

Bonney G, Macnab I. Hallux valgus and hallux rigidus: a critical survey of operative results. J Bone Joint Surg [Br] 1952; 34-B:366-85.

Corless JR. A modification of the Mitchell procedure. J Bone Joint Surg [Br] 1976; 58-B:138.

Eustace S, O'Byrne J, Stack J, Stephens MM. Radiographic features that enable assessment of first metatarsal rotation: the role of pronation in hallux valgus. Skeletal Radiol 1993; 22:153-6.

Golden GN. Hallux valgus, the osteotomy operation. Br Med J 1961; 1:1361-5.

Haines RW, McDougall A. The anatomy of hallux valgus. $J$ Bone Joint Surg [Br] 1954; 36-B:272-93.

Hardy RH, Clapham JCR. Observations on hallux valgus: based on a controlled series. J Bone Joint Surg [Br] 1951; 33-B:376-91.

Hardy RH, Clapham JCR. Hallux valgus predisposing anatomical causes. Lancet 1952; 1:1180-3.

Hattrup SJ, Johnson KA. Chevron osteotomy: analysis of factors in patients' dissatisfaction. Foot Ankle 1985; 5:327-32. 
Holmes GB Jr, Timmerman L, Willits NH. Practical considerations for the use of the pedobarograph. Foot Ankle 1991; 12:105-8.

Johnson KA, Cofield RH, Morrey BF. Chevron osteotomy for hallux valgus. Clin Orthop 1979; 142:44-7.

Kelikian H. Hallux valgus, allied deformities of the forefoot and metatarsalgia. Philadelphia, etc: WB Saunders, 1965.

Kilmartin TE, Barrington RL, Wallace WA. Metatarsus primus varus: a statistical study. J Bone Joint Surg [Br] 1991; 73-B:937-40.

Lapidus PW. Operative correction of the metatarsus primus varus in hallux valgus. Surg Gynecol Obstet 1934; 58:183-91.

Mann RA, Coughlin MJ. Hallux valgus and complications of hallux valgus. In: Mann RA, ed. Surgery of the foot. Fifth ed. St Louis, etc: CV Mosby, 1986; 65-131.

Meier PJ, Kenzora JE. The risks and benefits of distal first metatarsal osteotomies. Foot Ankle 1985; 6:7-17.

Myerson M, Allon S, McGarvey W. Metatarsocuneiform arthrodesis for management of hallux valgus and metatarsus primus varus. Foot Ankle $1992 ; 13: 107-15$.
Piggott H. The natural history of hallux valgus in adolescence and early adult life. J Bone Joint Surg [Br] 1960; 42-B:749-60.

Richardson EG. Disorders of the hallux valgus. In: Crenshaw AH, ed. Campbell's operative orthopaedics. Eighth ed. St Louis, etc: Mosby Yearbook, 1992:2615-92.

Rocyn Jones A. Hallux valgus in the adolescent. Proc R Soc Med 1948; 41:392-3.

Simmonds FA, Menelaus MB. Hallux valgus in adolescents. J Bone Joint Surg [Br] 1960; 42-B:761-8.

Thordarson DB, Leventen EO. Hallux valgus correction with proximal metatarsal osteotomy: two-year follow-up. Foot Ankle 1992; 13: 321-6.

Truslow W. Metatarsus primus varus or hallux valgus. J Bone Joint Surg $1925 ; 7: 98-108$

Vaughan CL, Davis BL, O'Connor JC. Appendix C: Commercial equipment for gait analysis. In: Dynamics of human gait. Human Kinetics Publishers, 1992: 107-25. 